\title{
P04.86. Socio-demographic variations in barriers to participation in an acupuncture clinical trial
}

\author{
T Tan*, S Xie, S Li, R Lam, J Farrar, J Mao \\ From International Research Congress on Integrative Medicine and Health 2012 \\ Portland, Oregon, USA. 15-18 May 2012
}

\section{Purpose}

As breast cancer survivors (BCS) increasingly use complementary and alternative medicine, randomized controlled trials (RCT) are needed to assess the safety and efficacy of these therapies to guide appropriate clinical use. However, many RCTs face poor patient accrual, especially among populations at risk for health disparities. The purpose of this study is to quantify the barriers to participation in an acupuncture clinical trial among $\mathrm{BCS}$, and to identify the socio-demographic factors associated with these barriers.

\section{Methods}

We conducted a cross-sectional survey study at an outpatient oncology clinic in an urban academic hospital among post-menopausal women on adjuvant aromatase inhibitors for stage I to III breast cancer.

\section{Results}

Of the 300 participants, 148 (49.8\%) were willing to participate in an acupuncture clinical trial. Despite high interest, perceived barriers towards participation were common and included presence of placebo (45.9\%), travel difficulty (45.6\%), home responsibilities (45\%), demanding job (35.6\%), lack of interest in acupuncture (27.2\%), and discomfort with experimentation (25.2\%). Socio-demographic factors were significantly associated with these barriers. While white participants were more likely to consider travel difficulty a barrier, non-white participants were more likely to consider discomfort with experimentation a barrier (both $\mathrm{p}<0.05$ ). Older participants were more likely to cite discomfort with experimentation and lack of interest in acupuncture as barriers, while younger participants were more likely to cite demanding job and home responsibilities as barriers

University of Pennsylvania Health System, Philadelphia, USA (all $\mathrm{p}<0.05$ ). In addition, women with lower education were more likely to report discomfort with experimentation, presence of placebo, and lack of interest in acupuncture as barriers (all $\mathrm{p}<0.05)$.

\section{Conclusion}

Although nearly half of respondents reported willingness to participate in an acupuncture clinical trial, significant barriers towards participation exist and differ among populations. Future studies must address these barriers to ensure effective accrual and improve the representation of individuals from diverse backgrounds.

Published: 12 June 2012

doi:10.1186/1472-6882-12-S1-P356

Cite this article as: Tan et al.: P04.86. Socio-demographic variations in

barriers to participation in an acupuncture clinical trial. $B M C$

Complementary and Alternative Medicine 2012 12(Suppl 1):P356.

Submit your next manuscript to BioMed Central and take full advantage of:

- Convenient online submission

- Thorough peer review

- No space constraints or color figure charges

- Immediate publication on acceptance

- Inclusion in PubMed, CAS, Scopus and Google Scholar

- Research which is freely available for redistribution
๑ 2012 Tan et al; licensee BioMed Central Ltd. This is an Open Access article distributed under the terms of the Creative Commons Attribution License (http://creativecommons.org/licenses/by/2.0), which permits unrestricted use, distribution, and reproduction in any medium, provided the original work is properly cited. 